\title{
ESTADOS, ALIANZAS Y DESIGUALDAD SUBNACIONAL: DOS PROVINCIAS ARGENTINAS EN PERSPECTIVA COMPARADA, 2003-2015
}

\author{
States, Alliances, and Subnational Inequality: Two Argentine \\ Provinces in Comparative Perspective, 2003-2015
}

\section{LUCAS GONZÁLEZ}

Universidad Católica Argentina/ Universidad Nacional de San Martín (UNSAM), Argentina

\section{MARCELO NAZARENO}

Universidad Católica de Córdoba/Universidad Nacional de Córdoba, Argentina

\begin{abstract}
RESUMEN
La desigualdad se distribuye de manera desigual en el territorio y los promedios nacionales oscurecen esta variación. Este estudio investiga qué factores a nivel subnacional pueden ayudar a explicar las diferencias en la desigualdad entre distritos. El trabajo analiza de que manera las coaliciones subnacionales resisten o apoyan políticas redistributivas de los gobiernos nacionales. El principal argumento es que el tipo de alianza gobernante nacional (regresiva o progresiva), incide en el nivel de desigualdad provincial, pero mediada por el tipo de coalición subnacional que apoye o resista a esa política nacional. Este argumento es examinado empíricamente a través del análisis de la configuración de las alianzas distributivas nacionales y subnacionales en dos provincias argentinas y en relación a las regulaciones de derechos laborales en el sector agrícola entre 2003 y 2015.
\end{abstract}

Palabras clave: Desigualdad, Alianzas, Relaciones Intergubernamentales, Derechos Laborales, Provincias, Argentina.

\begin{abstract}
Inequality is unevenly distributed across the territory and national averages obscure this variation. This study investigates which subnational level factors can help explain differences in inequality among districts. It analyzes how subnational coalitions resist or support national governments' redistributive policies. The main argument is that the type of national governing alliance (regressive or progressive) affects the level of provincial inequality, but mediated by the type of subnational coalition that supports or resists that national policy. This work empirically examines this claim analyzing the configurations of the national and subnational distributive alliances in two Argentine provinces and in relation to labor rights regulations in the agricultural sector between 2003 and 2015.
\end{abstract}

Keywords: Inequality, Alliances, Intergovernmental Relations, Labor Rights, Provinces, Argentina. 


\section{INTRODUCCIÓN}

Muchos países en América Latina bajaron notablemente la desigualdad en los 2000. Bolivia bajó su desigualdad, medida con el índice de Gini, en 20 puntos (de 0.63 a 0.43 entre 2005-2018) luego del gobierno de Evo Morales, un dirigente cocalero que sumó a sindicalistas y campesinos en su gobierno. El gobierno de Lula da Silva en Brasil también bajó la desigualdad en 13 puntos del índice de Gini (de 0.64 a 0.51, entre 2001-2014) en uno de los países más desiguales del mundo. Lula, un exdirigente sindical metalmecánico, también sumó a trabajadores y representantes de movimientos sociales a su gabinete. Algo parecido puede decirse de los gobiernos de Néstor y Cristina Kirchner en Argentina. Estos gobiernos, que también sumaron dirigentes sindicales y de movimientos sociales en sus gabinetes, bajaron la desigualdad de ingresos en Argentina en diez puntos del índice de Gini (de 0.50 a 0.40 entre 2003 y 2011) (datos de Gini de la World Income Inequality Database (WIID)). ${ }^{1}$

A pesar de la relevancia de estos logros en la región más desigual del mundo, la desigualdad está distribuida de manera muy desigual en el territorio y los promedios nacionales oscurecen esta variación. Si bien el índice de Gini cayó diez puntos en promedio en Argentina, Chaco redujo su desigualdad de ingresos en 16 puntos (de 0.52 a 0.36). Corrientes y Jujuy, a pesar de ser tan desiguales como Chaco al comienzo de la serie, redujeron sus índices de Gini en la mitad. De esa manera, el resultado es enormemente variado: Tierra del Fuego era bastante igualitaria para los estándares latinoamericanos y bajó mucho la desigualdad en este período; tiene un índice provincial de Gini (0.32 en 2011) similar a Canadá y Australia (OCDE 2019). Chaco, Salta y Corrientes eran muy desiguales. Pero Chaco redujo mucho la desigualdad y las otras dos provincias siguen siendo parte del grupo de provincias más desiguales $(0.45$ y 0.46 respectivamente), con índices similares a los de Guatemala y Malawi (SEDLAC 2018; UNU-WIDER 2018).

¿Qué explica estas enormes variaciones en la desigualdad al interior de los países? Las contribuciones de las investigaciones que explican cambios en la desigualdad son enormes, tanto en términos teóricos como empíricos ${ }^{2}$. Varios estudios académicos recientes coinciden en identificar el papel de las élites económicas en el aumento de la desigualdad en varios países (Hacker y Pierson 2010; Blofield 2011; Winters 2011; Page, Bartels y Seawright 2013; Fairfield 2015). Pero está menos claro quiénes son estas élites económicas y cómo generan más desigualdad.

Además, pocos trabajos abordan estas cuestiones a nivel subnacional. La mayoría de los estudios que abordan las explicaciones políticas de la desigualdad

Entre las políticas del gobierno nacional implementadas entre 2003 y 2011 que incidieron en la disminución de la desigualdad de ingresos podemos destacar: la reforma previsional por la cual se incorporaron al sistema más casi dos millones de personas, la Asignación Universal por Hijo y la política salarial.

2 Ver González y Nazareno (2018) para un resumen de la literatura más relevante sobre el tema. 
a nivel subnacional parecen hacer una "extrapolación" teórica y metodológica del nivel de análisis nacional al subnacional (Giraudy, Moncada y Snyder $2019)^{3}$. Ninguno de estos estudios explora en profundidad la posibilidad de que variables políticas específicas a nivel subnacional (que pueden no estar presentes a nivel nacional) puedan afectar la desigualdad. Este trabajo sostiene que las diferencias en la desigualdad subnacional no pueden explicarse únicamente mediante la extrapolación de factores que podrían estar presentes a nivel nacional. Es necesario incorporar factores provinciales específicos que puedan afectar la desigualdad dentro de cada unidad subnacional. Estas variables podrían complementar y eventualmente revisar los marcos analíticos a nivel nacional. Hasta donde sabemos, esta estrategia de investigación sobre las desigualdades subnacionales aún no se ha explorado.

Complementando y ampliando trabajos anteriores (González y Nazareno 2021), argumentamos que las alianzas gobernantes que se expresan en la composición de los gabinetes gubernamentales y/o los puestos más altos de las estructuras político administrativas también juegan un rol importante en el nivel subnacional. Sólo que tales alianzas se configuran a partir de una dinámica y una estructura específicamente subnacional que no necesariamente coincide con las que son propias del nivel nacional. De este modo, a igualdad de otros factores, esperamos que las desigualdades subnacionales sean el resultado de interacciones entre las presiones distributivas de alianzas nacionales y alianzas subnacionales.

El trabajo analiza de que manera las coaliciones redistributivas subnacionales resisten o apoyan políticas redistributivas de los gobiernos nacionales. Nuestro argumento teórico sostiene que el tipo de alianza gobernante nacional, que puede tener intereses de distribución regresivos o progresivos (las llamaremos, respectivamente, alianzas regresivas o progresivas), incide en el nivel de desigualdad provincial, pero mediada por el tipo de coalición subnacional que apoye o resista a esa política nacional. Por ello, podemos esperar una desigualdad más alta cuando estamos frente a alianzas gobernantes con intereses regresivos en ambos niveles de gobierno, una desigualdad más baja cuando ambas alianzas de gobierno tengan intereses de redistribución progresivos (alianzas progresivas) y niveles intermedios cuando existan combinaciones de ambas (ver Tabla 1 abajo).

Este argumento es examinado empíricamente a través del análisis de la configuración de las alianzas distributivas nacionales y subnacionales en dos provincias argentinas y en relación a las regulaciones de derechos laborales en el sector agrícola. Analizamos este sector en particular, por un lado, porque es uno de los más importantes generadores de empleo informal; esta variable (empleo informal), junto con la variable empleo agrícola, correlacionan muy fuertemente con desigualdad (González y Nazareno 2018). Además, por otro 
lado, porque en esta política en particular las relaciones entre niveles de gobierno son clave para decidir el resultado: el gobierno nacional puede regular (o no) derechos laborales para el sector agrícola, pero depende de los gobiernos provinciales para hacer cumplir esas normas. Esto también sucede en otros sectores, como la protección del medioambiente (Fernández Milmanda y Garay 2019; Alcañiz y Gutiérrez 2020).

Concentramos nuestro análisis entre 2003 y 2015; un período en el que el gobierno federal implementó políticas para reducir la desigualdad. Seleccionamos este período no solo porque tenemos datos disponibles, sino fundamentalmente porque nos permite explorar cuándo y cómo las élites provinciales resisten o apoyan las políticas redistributivas nacionales. Durante el período estudiado, una alianza en el gobierno nacional intentó regular derechos laborales para el sector, pero dependió de los gobiernos provinciales para hacer cumplir los mismos. En el trabajo describimos cómo esta alianza nacional decidió regular derechos laborales en el sector agrícola y la manera en que las alianzas subnacionales apoyaron o resistieron esos intentos.

Las provincias argentinas son particularmente valiosas para estudiar las variaciones en la desigualdad. Primero, como vimos, hay una enorme variación en el resultado entre los casos y a través del tiempo. En segundo lugar, al comparar las provincias dentro de un país, hay muchas variables que pueden controlarse porque no hay variación entre ellas, como factores culturales (relevantes en otros países federales como India, Sudáfrica y Nigeria), instituciones federales de gobierno, estructuras económicas y otras variables no observables, pero posiblemente relevantes, que pueden variar sustancialmente de un país a otro pero que a menudo no se miden o se miden mal en investigaciones comparadas (Snyder 2001: 93-110; Weitz-Shapiro 2012: 572). En tercer lugar, el estudio de casos provinciales nos permitirá sumar precisiones a nuestro argumento teórico y entender los detalles sobre cómo opera el vinculo causal entre las variables. Estas son contribuciones clave, que podrán complementarse a las de estudios cuantitativos previos (Kelly y Witko 2012; Sátyro 2013; Calvo y Moscovich 2017; González y Nazareno 2018, 2021), particularmente aquellos que indican una correlación entre intereses y condiciones económicos y desigualdad.

En la siguiente sección, presentamos algunas discusiones en la literatura existente e identificamos algunas brechas analíticas. Con base en esta revisión, presentamos nuestro argumento teórico, que conecta coaliciones distributivas y desigualdad. Exploramos las variaciones subnacionales en la desigualdad, en las alianzas subnacionales de gobierno y en el apoyo o rechazo de las políticas nacionales de parte de los gobiernos subnacionales mediante un estudio comparativo de dos casos clave, Chaco y Corrientes. Estas son provincias vecinas, vinculadas histórica, económica y culturalmente, que muestran la mayor variación en la desigualdad de ingresos. Argumentamos que las relaciones entre las alianzas distributivas nacionales y las provinciales pueden ayudarnos a entender cómo ocurrieron algunas de estas diferencias. 
Es importante aclarar que no pretendemos identificar todos los factores que podrían explicar las diferencias en la desigualdad en Chaco y Corrientes (ya que miramos la implementación de una política muy específica) sino que buscamos desentrañar algunos mecanismos causales que median entre la sanción formal de políticas distributivas en un sistema federal y el efectivo resultado redistributivo de tales políticas en los territorios subnacionales. Es en esta mediación que la interacción entre niveles de gobierno debe asumirse como un dato crucial. No obstante las limitaciones de estudiar dos casos y en relación a una sola política, creemos que, al dar cuenta de las diferencias en la recepción de esta política por parte de las provincias, damos un paso importante en la dilucidación de los mecanismos a través de los cuales se constituye la desigual distribución de la desigualdad en el país. En base a estas reflexiones y resultados, en la sección final, presentamos algunas conclusiones y exploramos las implicaciones comparativas de nuestro estudio.

\section{ANTECEDENTES DE INVESTIGACIÓN}

El análisis de la política subnacional para explicar los niveles y las dinámicas de la desigualdad es relativamente reciente en América Latina y son muy escasos los estudios en la región (aun incluyendo a los Estados Unidos) que adoptan esta perspectiva. Los que lo hacen se ubican en alguna de tres alternativas analíticas diferentes que podemos distinguir en los estudios subnacionales comparados.

Una de ellas busca explicar los niveles de desigualdad subnacionales recurriendo a factores políticos propios de este nivel, como la densidad sindical (Kelly y Witko 2012), la orientación ideológica de los gobiernos estatales y los márgenes electorales subnacionales (Kelly y Witko 2012; Sátyro 2013).

Las restantes estrategias se inscriben en el marco de las llamadas teorías multinivel, que combinan factores nacionales y subnacionales para construir explicaciones más sólidas de los procesos o resultados de interés (Giraudy, Moncada y Snyder 2019: 18-19). En la versión “desde abajo" (bottom up) de estas teorías, se ofrecen explicaciones de resultados nacionales a partir de variables subnacionales (Beramendi, Rogers y Díaz-Cayeros 2017; Giraudy, Moncada y Snyder 2019: 19).

Por su parte, en la versión "desde arriba" (top down) de las teorías multinivel, se busca establecer el efecto subnacional de factores nacionales. Giraudy, Moncada y Snyder (2019: 21) distinguen dos clases de análisis de este tipo. Una que establece efectos subnacionales homogéneos y otra que establece efectos subnacionales heterogéneos. En este último caso, y en referencia a la desigualdad subnacional, lo que se intenta determinar es el modo en el que la política subnacional procesa y modifica los impulsos o políticas redistributivas con origen en el nivel nacional, como en el trabajo de Calvo y Moscovich (2017). En este caso, la variable subnacional clave es el nivel de protesta. 
Por cierto, todas estas estrategias no son contradictorias sino complementarias. Sin embargo, el valor analítico de la estrategia "desde arriba" (top down) heterogénea parece indudable para entender los vínculos entre política y desigualdad en los niveles subnacionales. Resulta difícil pensar que la desigualdad en estos niveles esté desvinculada de la política y las políticas nacionales. Pero, al mismo tiempo, parece evidente que "(...) los actores e instituciones subnacionales no son (...) receptores pasivos de políticas e iniciativas nacionales sino agentes activos con el potencial de involucrarse, desafiar, y aún modificar las fuerzas 'desde arriba' (top down). Por lo tanto, una variedad de diferentes resultados se dará entre las unidades subnacionales dependiendo de los actores e instituciones que existan y operen en ellas" (Giraudy, Moncada y Snyder 2019: 21).

\section{DESIGUALDAD SUBNACIONAL: ALIANZAS GOBERNANTES, NIVELES DE GOBIERNO Y REDISTRIBUCIÓN}

El estado subnacional, particularmente en los sistemas federales como el de la Argentina, posee una serie de recursos (administrativos, fiscales, legales y político-institucionales) que pueden incidir decisivamente sobre la implementación de muchas políticas nacionales (Benton 2003; Fernández Milmanda y Garay 2019; Alcañiz y Gutiérrez 2020). Es razonable asumir, entonces, que los actores socio-políticos subnacionales intentarán que el estado provincial refuerce o neutralice, según cuáles sean sus intereses, los impulsos redistributivos (regresivos o progresivos) del gobierno nacional. En efecto, quienes tengan recursos políticos de algún tipo localizados territorialmente y valiosos en la esfera subnacional, intentarán hacerlos valer en esa esfera e incidir en las acciones (o no acciones) estatales relativas a las políticas nacionales, independientemente de los recursos que pudieran desplegar en el nivel nacional. Más aún, si tuvieran más recursos políticos que fueran operativos en el nivel subnacional antes que en el nacional, estos actores intentarán desplazar las esferas de decisión hacia aquel nivel. Como afirma Pierson (1995: 452) (parafraseando a Schattschneider) en su estudio sobre las políticas sociales en sistemas federales, "(...) los actores sociales estarán ávidos de cambiar el ámbito de las decisiones políticas a la arena que mejor favorezca sus intereses."

Diferentes perspectivas teóricas abordaron cómo identificar a estos actores, el modo en que logran penetrar al estado con sus propias preferencias de políticas públicas, si hay o no actores estructuralmente aventajados al respecto y hasta dónde el estado es, también estructuralmente, receptivo o no a tales demandas. Desde una perspectiva ya clásica, el análisis parte de lo que Gourevitch (1993) llama la "imagen de la producción," esto es, el conjunto de actores socio-económicos cuyas preferencias de políticas están en función de su lugar en la estructura económica doméstica e internacional. En función de estas preferencias, "estos actores, deseosos de llegar a un resultado político particular, forman coaliciones que incluyen concesiones y negociaciones con objeto de movilizar el consenso necesario para prevalecer" (Gourevitch 
1993: 62). Los modelos de desarrollo y distributivos, entonces, emergerán y se consolidarán según las líneas definidas por la que sea, en su momento, la "coalición ganadora."

Un aspecto de gran relevancia para nuestro esquema analítico es determinar si los actores intentarán incidir "desde afuera" sobre el estado para llevar adelante sus políticas preferidas, o bien se inclinarán por tener cierto control directo sobre sus centros de decisión (al menos los más directamente vinculados a sus intereses). El concepto de "alianza de gobernante" de O'Donnell (1997) capta, a nuestro juicio, este último aspecto, para nosotros crucial de la política coalicional. Una alianza gobernante se define como aquella "(..) que impone, a través del sistema institucional del estado, políticas conformes a las orientaciones y demandas de sus componentes" (O'Donnell 1997: 65). Coaliciones de actores sociales (o coaliciones sociales) y alianzas gobernantes, entonces, son dos conceptos diferentes. Mientras las coaliciones, aún cuando sean amplias y firmes, tienen un largo y complejo camino que recorrer antes de transformar sus preferencias en políticas estatales (esto es, convertirse en coaliciones efectivamente ganadoras), las alianzas gobernantes han recorrido en buena medida este camino y podría decirse, exagerando a modo ilustrativo, que las políticas "son" sus preferencias.

A igualdad de otras condiciones, las políticas del estado se orientarán más en línea con los intereses de las alianzas gobernantes que de los de aquellas que operan desde "fuera" del estado. Por cierto, esto no implica desconocer que los factores de poder diferentes del poder estrictamente político tienen incidencia importante sobre las políticas distributivas y, por ende, sobre los niveles de desigualdad. No obstante, contra lo que parece ser la tendencia dominante hoy en la literatura de la incidencia de los intereses sectoriales sobre el estado, en la que se destaca la importancia del "poder económico" por sobre la del "poder político" (Acemoglu y Robinson 2006; Hacker y Pierson 2010; Blofield 2011; Winters 2011; Page, Bartels y Seawright 2013; Ansell y Samuels 2014; Fairfield 2015; entre otros), lo que sostenemos aquí es que los actores sociales aspiran, como un objetivo político central, a constituir alianzas gobernantes.

En línea con la perspectiva que sostiene que la autonomía del estado depende de condiciones históricas (Skocpol 1989), podemos hablar más bien de un continuo, con extremos (analíticos) de total autonomía por un lado y absoluto control instrumental por parte de una alianza gobernante, por el otro. De este modo, esperamos elevados niveles de desigualdad cuando estemos frente a alianzas gobernantes con intereses de distribución regresivos (a las que llamaremos, justamente alianzas regresivas) y de redistribución progresiva cuanto las alianzas de gobierno tengan intereses en este sentido (alianzas progresivas). Cuando no hubiera alianzas gobernantes, estaremos frente a estados autónomos en los que se asume que los intereses estrictamente político-electorales o de preservación del poder político (Skocpol 1989) de los gobernantes juegan un rol relevante (aunque, por cierto, no exclusivo). En estos casos, la primacía de políticas redistributivas progresivas o regresivas dependerá de factores como 
el signo ideológico de los gobiernos y las coaliciones sociales que interactúan, desde "fuera" del estado, con ellos.

Un punto importante para señalar es que el control total del estado por los actores que conforman una alianza gobernante es una referencia analítica que muy improbablemente emerja como realidad histórica (tan improbable como la de un estado "totalmente" autónomo). Lo esperable es que una alianza gobernante incluya no sólo actores sociales provenientes de la "imagen de la producción," sino también actores partidarios, con intereses específicamente político-electorales, que interactúan con los intereses más puramente corporativos de los actores sociales que forman parte de la alianza de gobierno. Esto es, una alianza de gobierno es (casi siempre) una alianza entre una coalición social y una élite política (relativamente autónoma). Así, las alianzas gobernantes sintetizan dos diferentes opciones analíticas, hasta ahora excluyentes, desde las cuales se ha abordado la acción estatal: o bien un estado capturado (actores incidiendo desde "dentro" del estado), o bien un estado autónomo (operando, en tanto "actor," según sus propios objetivos e intereses). En una alianza gobernante convergen, entonces, aspectos heterónomos y autónomos de la configuración estatal, sin perjuicio de su orientación redistributiva regresiva o progresiva según sea su composición social. Esto abre un espacio analítico para el estudio de conflictos entre intereses propiamente políticos y otros socio-corporativos dentro de una alianza gobernante. La emergencia de estos conflictos, su naturaleza y hasta dónde compromete (o no) la orientación distributiva de la alianza e incluso su propia continuidad es, creemos, una cuestión empírica.

Los trabajos que refieren a coaliciones o alianzas para dar cuenta de las diferencias en las políticas redistributivas y los consiguientes niveles de desigualdad se ubican casi exclusivamente en el nivel nacional (O'Donnell 1997; Iversen y Soskice 2006; Lupu y Pontusson 2011; Huber y Stephens 2012). El uso del esquema analítico coalicional para dar cuenta de la dinámica de las desigualdades en el nivel subnacional es hoy, hasta donde sabemos, inexistente, al menos en el contexto latinoamericano. En función de ello, creemos que es posible hacer un conjunto de proposiciones metodológicas y analíticas con validez general (al menos para los federalismos de América Latina) en relación a las coaliciones y alianzas subnacionales y su incidencia sobre la desigualdad subnacional.

1. Las imágenes de producción en los niveles subnacionales tenderán a ser muy disímiles dada la despareja dinámica e intensidad de los procesos de desarrollo nacionales. Esto implica que habrá grandes diferencias, en principio, en las características y dinámicas de las alianzas gobernantes y los modelos distributivos que impulsan en los diferentes ámbitos subnacionales.

2. Los ámbitos subnacionales serán la sede de impulsos distributivos, regresivos o progresivos, según las características de las alianzas gobernantes que se constituyan en ellos. De allí que, contrariamente a lo que es común en la literatura sobre América Latina (Mann 2004; Santos 2010), no vemos a los espacios políticos subnacionales "naturalmente" dominados por las élites conservadoras que se refugian allí para preservar sus privilegios. 
3. Como en los casos nacionales, los procesos de construcción del estado y los rasgos estructurales que marcan las trayectorias estatales son de especial relevancia. La "historia," normalmente muy disímil, de configuración de los estados subnacionales tiene, entonces, un papel relevante respecto de las imágenes de producción, nivel de asociación, dinámica político-partidaria y posibilidades de construcción de alianzas gobernantes, de una parte, y de los grados estructurales de autonomía de los aparatos estatales, de la otra.

4. Los signos partidarios de los gobiernos provinciales, por sí mismos, no son un buen predictor del contenido redistributivos regresivo o progresivo de los diferentes gobiernos, a menos que estemos en casos de un elevado grado de autonomía estatal. En otros términos, el signo político-ideológico de los gobiernos pierde relevancia en la medida que estos integren alianzas gobernantes en las cuáles se canaliza de modo directo el interés de ciertos actores socio-económicos.

5. Las desigualdades en el nivel subnacional dependerán de los impulsos de políticas distributivas que provienen tanto de las alianzas gobernantes nacionales como subnacionales, en tanto ambas procesan políticamente los impulsos distributivos (regresivos o progresivos) de las alianzas del otro nivel. Sin embargo, esta relación no es simétrica: mientras es previsible que las alianzas gobernantes subnacionales reaccionen intensamente y de modo específico en relación a iniciativas nacionales, lo inverso no necesariamente es cierto, ya que las alianzas nacionales deben dar cuenta de escenarios más complejos; entre ellos, su relación según el modelo de "juegos anidados" (Tsebelis 1991), con la totalidad de las jurisdicciones subnacionales. Esta interacción entre los niveles se esquematiza en la Tabla 1.

Tabla 1. Alianzas gobernantes nacionales, alianzas subnacionales y desigualdades "esperadas" en el nivel subnacional

\begin{tabular}{ccc}
\hline & $\begin{array}{c}\text { Alianzas Progresivas } \\
\text { Nacionales }\end{array}$ & $\begin{array}{c}\text { Alianzas Regresivas } \\
\text { Nacionales }\end{array}$ \\
\hline $\begin{array}{c}\text { Alianzas Progresivas } \\
\text { Subnacionales }\end{array}$ & BAJA Desigualdad & Desigualdad MEDIA \\
$\begin{array}{c}\text { Alianzas Regresivas } \\
\text { Subnacionales }\end{array}$ & Desigualdad MEDIA & ALTA Desigualdad \\
\hline
\end{tabular}

\section{CONTEXTO HISTÓRICO: LA ESTRUCTURACIÓN DE LOS ESTADOS SUBNACIONALES Y LAS BASES SOCIO-POLÍTICAS DE LAS ALIANZAS GOBERNANTES}

Como dijimos más arriba, las alianzas gobernantes no se configuran en un vacío histórico y político, sino que emergen y se consolidan en el contexto de una estructura configurada históricamente según la ocupación original de los territorios provinciales, la estructura socio-económica que surge a partir de tal 
ocupación y la organización y distribución del poder político-estatal asociado a dicha estructura. Siguiendo la tradición de varios autores (Skocpol 1989; Pierson 1995; Acemouglu y Robinson 2006), creemos que estos antecedentes históricos son clave para desarrollar nuestro argumento teórico y ajustarlo a los casos que estudiamos. ${ }^{4}$

1. En un extremo están las tradicionales economías agrícolas de plantación en las que las élites económicas, típicamente terratenientes, eran muy poderosas. Los propietarios en estas economías controlaban la producción de las plantaciones (por ejemplo, caña de azúcar, tabaco, yerba mate, arroz), así como las milicias locales. Los estados provinciales en estas economías de plantación fueron históricamente débiles en relación con las élites económicas. Las élites económicas, cruciales durante la formación del estado provincial, configuraron estrechas alianzas con las elites políticas (con las cuales normalmente tenían fuertes lazos sociales y familiares) para asegurar la propiedad de sus tierras, regular los impuestos sobre sus propiedades y reprimir los derechos laborales en la provincia para garantizar mano de obra barata.

2. En el otro extremo, están los llamados "espacios vacíos," ocupados principalmente por pueblos originarios en tierras poco productivas. Allí, las élites políticas nacionales (blancas) crearon nuevas provincias para consolidar la ocupación del territorio nacional, controlar las poblaciones originarias, prevenir invasiones extranjeras y (luego) asegurar la (sobre)representación política para sus partidos en el congreso nacional. En estas provincias, las élites económicas fueron prácticamente inexistentes, lo que favoreció la consolidación de élites políticas más autónomas ( $\mathrm{y}$ a veces profesionalizadas) predispuestas a constituir alianzas progresivas con los sectores sociales predominantes en la imagen de producción (sindicatos de trabajadores públicos, organizaciones sociales, pequeños productores, etc.).

3. Un tercer tipo de territorio y estructura económica corresponde a espacios donde la población originaria fue aniquilada o expulsada de tierras productivas y donde los colonos extranjeros (generalmente blancos) desarrollaron una producción agrícola intensiva en capital. Es más probable que esta forma de producción esté asociada no solo a la urbanización y el desarrollo industrial (Moore 1966) sino también a una estructura política más "pluralista" (Dahl 1961). En estas economías con una imagen de la producción diversificada y compleja, las alianzas político económicas tienden a ser más diversas e inestables. Los intereses diversificados y a menudo cambiantes de los diferentes actores de esta imagen les impiden construir coaliciones sólidas y duraderas. No obstante, dado que por su trayectoria histórica no estamos en presencia de

\footnotetext{
Lo que sigue es una modelización de las dinámicas históricas socio-políticas y económicas territoriales de la Argentina en base a la consulta de literatura relevante sobre esta cuestión (Balán 1978; Collado 2006; Cao y Vaca 2006; Bucciarelli y Favaro 2008; Chazarreta 2012). Como toda modelización, implica la simplificación de procesos complejos, que dejan de lado ciertas especificidades históricas que diferencian a los territorios para privilegiar los rasgos comunes que permiten la construcción de tipologías analíticamente relevantes.
} 
élites políticas con alto grado de autonomía, estas se mueven en el contexto de alianzas lábiles y cambiantes cuando no ambiguas en su composición social. Por lo tanto, esperamos que, en este tipo de estructura económica y política, la desigualdad de la intervención estatal ex-post sea relativamente similar a la desigualdad ex-ante, menor que en las economías de plantación con coaliciones regresivas fuertes y mayor que la de los espacios vacíos con coaliciones redistributivas fuertes.

4. Los grandes terratenientes en las economías de plantación prefieren armar alianzas regresivas entre los gobiernos nacionales y los provinciales porque están interesados en menores impuestos y menores gastos del gobierno en bienes públicos (por ejemplo, inversión social). Los impuestos más bajos aumentan directamente los rendimientos económicos de los grandes propietarios (Fairfield 2015) y la inversión en bienes públicos apenas los beneficia (Beramendi, Dincecco y Rogers 2016). De hecho, la inversión social puede crear escasez de mano de obra (Galor, Moav y Vollrath 2009) porque los trabajadores más educados pueden emigrar más fácilmente a los centros urbanos (Pardelli 2018: 9).

5. Los grandes propietarios también impulsan alianzas regresivas para limitar los derechos laborales en sus distritos. En los países federales, en particular, tienden a resistir las leyes laborales nacionales para reprimir los derechos laborales en la provincia y garantizar mano de obra barata.

6. Resumiendo lo anterior, las coaliciones de gobierno dependen de la fortaleza relativa de cada sector. En lugares donde las élites económicas fueron muy poderosas, como en las economías de plantación, las alianzas tienden a ser predominantemente regresivas. En los casos en que éstas fueron débiles o inexistentes, como en las provincias nuevas, y los aparatos estatales más autónomos, se abre la posibilidad de la constitución de alianzas de gobierno con representantes de sindicatos, movimientos sociales, pequeños productores y con orientaciones predominantemente redistributivas, contrarias a los intereses de las (relativamente débiles) elites económicas dominantes.

7. No estamos argumentando que podemos conectar eventos ocurridos en el momento de la ocupación del territorio para explicar niveles actuales de desigualdad en las provincias. Más bien, intentamos ubicar a cada provincia en un grupo diferente, a partir del cual podemos identificar diferentes configuraciones entre la estructura económica y las alianzas de gobierno, tanto nacionales como subnacionales. Argumentamos que estas situaciones ideales están asociadas a diferentes configuraciones de alianzas gobernantes y probabilidades de determinados niveles de desigualdad. Esperamos que las provincias con economía de plantación o con grandes industrias extractivas (mega-minería, petróleo o gas) y alta concentración económica, en las que las élites económicas configuran las alianzas de gobierno, tengan más desigualdad, aun cuando haya alianzas redistributivas nacionales, en relación con las provincias donde las elites políticas conforman alianzas redistributivas con sindicatos, movimientos 
sociales, y pequeños productores y donde los aparatos estatales tienen una trayectoria histórica de mayor autonomía.

\section{DOS CASOS Y UN SECTOR PRODUCTIVO}

Sobre la base del marco analítico y el contexto histórico presentado en la sección anterior, analizamos dos casos clave, Chaco y Corrientes. Los seleccionamos porque las principales variables muestran una gran variación entre ellos y a lo largo del tiempo. En relación a la desigualdad, Chaco y Corrientes se encontraban entre las provincias más desiguales del país al inicio de la serie (ver Figura 1). Pero mientras Chaco redujo su desigualdad de ingresos en 16 puntos (de 0.52 a 0.36), Corrientes redujo su índice de Gini en la mitad de lo que logró Chaco (de 0.50 a 0.42). Hoy, Corrientes está entre las dos provincias más desiguales y Chaco se encuentra entre las tres más igualitarias (ver Figura 2).

Figura 1. Desigualdad Interpersonal en las Provincias Argentinas (2003-2011)

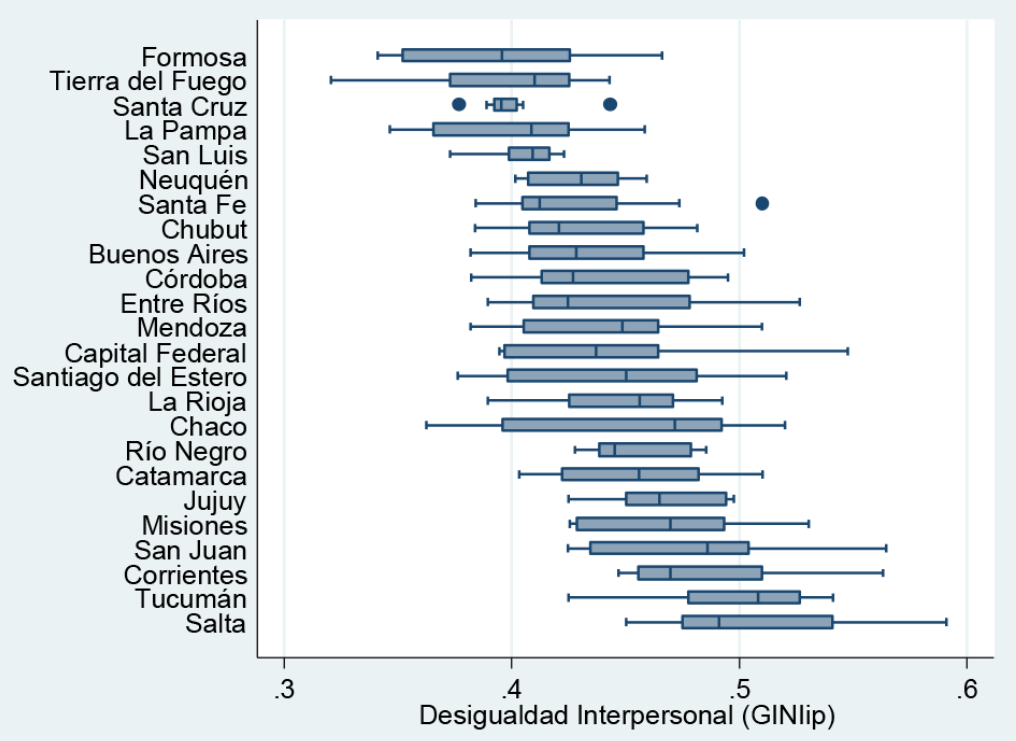

Fuente: elaboración propia en base a datos de EPH de Calvo y Moscovich (2017) 
Figura 2. Cambios en la Desigualdad en las Provincias Argentinas (2003-2011)

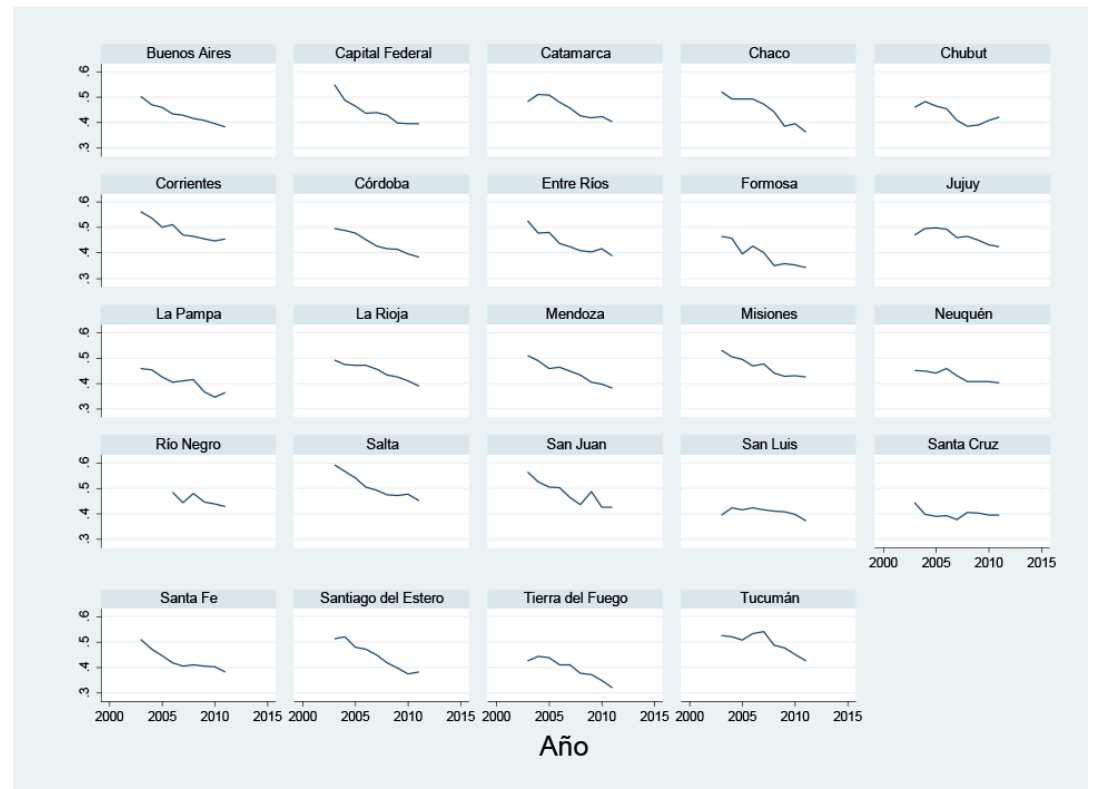

Fuente: elaboración propia en base a datos de EPH de Calvo y Moscovich (2017).

Por otro lado, la variable independiente principal también muestra variación entre los casos. Mientras que Chaco estuvo gobernado por una coalición progresiva durante este periodo, Corrientes estuvo en manos de una coalición regresiva. Además de estas diferencias, hay otros aspectos aún más llamativos: son provincias vecinas, vinculadas histórica, económica y culturalmente, separadas entre sí por el río Paraná. Al comparar estos casos dentro de un país, hay muchas variables (como aspectos culturales, estructura económica o instituciones federales) que pueden controlarse porque no hay variación entre ellas. La selección de estos casos nos permite controlar algunas variables presentadas como clave por la literatura, tener variación en los resultados para presentar un argumento teórico general y mostrar detalles clave de la conexión causal, particularmente sobre las relaciones entre el tipo de alianzas nacional y la resistencia o apoyo de las provinciales a las políticas implementadas por aquellas.

Corrientes es una de las provincias más antiguas de Argentina. Sus élites participaron activamente en el proceso de independencia, las posteriores guerras civiles y las luchas que llevaron a la formación de la Confederación Argentina. Su capital, Corrientes, fue fundada en 1588, uno de los primeros asentamientos coloniales en el territorio nacional. El territorio adquirió el estatus de provincia en 1821. Su primer gobernador fue Juan José Fernández Blanco, hijo de un rico comerciante español. Durante la colonización, los jesuitas españoles crearon misiones, que influyeron en las formas iniciales de producción y su estructura social. 
Poderosos terratenientes y élites políticas se han entrelazado históricamente en una estable alianza gobernante en Corrientes. De hecho, "la mayoría de las familias políticas provinciales pertenecen a una oligarquía terrateniente y a las propias empresas agrícolas" (Behrend 2011: 163). Los Romero Feris, por ejemplo, una familia política dominante en la provincia, han estado históricamente vinculados a una gran empresa ganadera.

Chaco es una provincia nueva. Alcanzó el estatus de provincia recién en 1952. Resistencia, la capital, fue fundada en 1878 por colonos italianos. Los territorios de la provincia se obtuvieron de Paraguay en 1865, después de que este país perdió la guerra de la Triple Alianza contra Argentina, Brasil y Uruguay. Estas tierras eran parte de lo que se denominaba "territorio nacional" (es decir, no tenían autonomía política, fiscal o administrativa y estaban bajo la jurisdicción del gobierno del gobierno nacional) desde 1872. Los gobernadores del territorio nacional durante este período fueron militares, que intentaron dominar a las poblaciones originarias, incorporar nuevas tierras a la producción nacional y evitar la expansión de potencias extranjeras.

La estructura económica de Corrientes es principalmente agraria, basada en grandes plantaciones. Los principales productos económicos son cultivos tradicionales como arroz, té, yerba mate y tabaco. Produce alrededor del 70 por ciento de los tabacos oscuros en el país, casi el 50 por ciento del arroz total y alrededor del 15 por ciento del total de la yerba mate (MECON 2018).

Las grandes empresas agrícolas son muy relevantes en comparación con las pequeñas. Corrientes tiene 27 grandes empresas agrícolas (de 50 a 200 empleados) registradas por año. Chaco tiene cinco veces menos que eso (5 en promedio). Corrientes tiene un promedio de 1,437 pequeñas empresas agrícolas registradas por año (2007-2017), mientras que Chaco casi duplica esa cifra (tiene 2,139). Casi el 80 por ciento de las unidades agrícolas de Chaco son históricamente pequeñas, principalmente algodón y quebracho. Estas unidades tienen un promedio de 349 hectáreas, en comparación con las 450 hectáreas en Corrientes (DDA Proinder 2007: 50).

El empleo agrícola en Corrientes representa un 20 por ciento promedio del empleo total (1996-2014), con el valor más bajo del 17 por ciento en 2014, en comparación con el 10 por ciento en Chaco en este mismo año. La informalidad laboral de todos los sectores fue del 38 por ciento en 2015 en Corrientes, 5 puntos superior al promedio del país (SSPE 2016: 3). En Chaco, el grado de informalidad en el mercado laboral fue de 27.3 por ciento en el $2^{\circ}$ trimestre de 2017, 6.4 puntos porcentuales menos que el nacional (MECON 2018b).

Analizamos el sector agrícola en particular porque es uno de los más importantes generadores de empleo informal y trabajo no registrado del país (una variable que correlaciona muy fuerte con desigualdad), con una mayoría de trabajadoras/es en condiciones de vida por debajo de la línea de pobreza. Además, el gobierno nacional intentó regular derechos laborales para el sector 
(como veremos en breve), pero dependió de los gobiernos provinciales para hacer cumplir los mismos.

Trabajos previos sugieren que la implementación de leyes nacionales depende de la capacidad del estado subnacional (Amengual 2016; Alcañiz y Gutiérrez 2020), la alineación política entre autoridades nacionales y subnacionales (Niedzwiecki 2018), los incentivos electorales de los políticos subnacionales (Smulovitz 2015; Holland 2016) o la movilización social y las coaliciones entre sectores productivos y gobernadores en las provincias (Fernández Milmanda y Garay 2019).

No obstante, la mayoría de estos factores no parecen tener suficiente potencia explicativa para nuestros casos. Algunos indicadores de capacidad estatal revelan que no hay diferencias sustantivas entre Corrientes y Chaco. Chaco tiene marginalmente más empleados públicos por habitante (49 versus 48 por cada 1000 habitantes, en promedio entre 1987 y 2015) e invierte más gasto social per cápita que Corrientes (posibles indicadores de capacidad estatal; ver datos más abajo). Pero las dos provincias reciben valores muy similares de transferencias federales (éstas representan 72 y 74 por ciento del presupuesto total promedio, para Chaco y Corrientes respectivamente), tienen ingresos provinciales casi idénticos (que representan casi el 10 por ciento del presupuesto total promedio entre 1983 y 2013) y valores parecidos de gasto total per cápita (1,400 y 1,100 USD entre 1993 y 2013, respectivamente). Valores relativamente similares en capacidad estatal no pueden explicar las diferencias en desigualdad que tienen ambas provincias.

Las relaciones partidarias pueden ayudar a entender tensiones y conflictos políticos. De hecho, las administraciones de la Unión Cívica Radical (UCR) de Corrientes, por ejemplo, tuvieron relaciones por momentos tensas con el gobierno nacional de los Kirchner. Pero estas dos provincias han tenido variación en la alineación política con el gobierno nacional y en los posibles incentivos electorales a lo largo del tiempo y, sin embargo, tienen resultados muy diferentes en relación a la desigualdad en sus distritos y, como veremos, respecto a la cooperación con el gobierno nacional en la implementación de políticas redistributivas. Creemos que las relaciones entre las alianzas distributivas nacionales y las provinciales pueden ayudar a entender cómo se definen estas diferencias.

En relación a la movilización social, tenemos datos de protestas (cortes de rutas) entre 2003 y 2007 (Datos del Centro de Estudios de Nueva Mayoría) y huelgas o paros entre 2006 y 2017 (Datos de la Dirección de Estudios de Relaciones del Trabajo, Ministerio de Trabajo). Corrientes tuvo un promedio de 7.2 cortes de rutas y 17 paros o huelgas por año. Chaco tuvo 24.6 cortes de rutas y 44 paros o huelgas promedio por año. Estos datos parecen apoyar argumentos sobre el rol de la conflictividad social y la presión de grupos sociales y su influencia en la redistribución y la desigualdad (Calvo y Moscovich 2017; Fernández Milmanda y Garay 2019). Sin desconocer la fortaleza de esta posición, presentamos un argumento complementario. No pretendemos ver el rol de las presiones de 
grupos sociales desde afuera del estado sino el rol de las alianzas gobernantes desde dentro del mismo. En la próxima sección describimos cómo una alianza nacional decidió regular derechos laborales en el sector agrícola y la manera en que las alianzas subnacionales apoyaron o resistieron esos intentos.

\section{La alianza federal y las regulaciones nacionales: el régimen de trabajo agrario}

La regulación de los derechos laborales de los trabajadores rurales ha sido una puja redistributiva intensa a lo largo de la historia de un país esencialmente agroexportador. Una alianza redistributiva había establecido estos derechos en 1944 (mediante el llamado "estatuto del peón de campo"), pero un decreto especial de la dictadura militar $(22,248 / 80)$, derogó al estatuto en 1980 y reguló al sector mediante un régimen que establecía menos beneficios que la ley nacional de contratos de trabajo (ver Fundamentos en el Diario de Sesiones de la Cámara de Diputados (DSCD en adelante), Reunión 13a , 225-226). La alianza que implantó este decreto fue regresiva, agroexportadora, militar y autoritaria. Esta coalición claramente prefería mano de obra barata y condiciones de alta informalidad en el sector agrícola.

El status quo jurídico en materia de derechos laborales de los trabajadores de campo iniciado por esa coalición se mantuvo por 20 años. A partir de 2003 se constituyó una nueva alianza gobernante redistributiva nacional (gobierno de un partido con una fuerte agenda redistributiva, aliado con varios sindicatos importantes y algunos movimientos sociales) que incorporó en su agenda la modificación de este statu quo.

En 2011, la presidenta Cristina Fernández de Kirchner envió al Congreso Nacional un proyecto de ley para implementar el llamado Régimen de Trabajo Agrario. El proyecto de ley definió las regulaciones federales relacionadas con derechos laborales en el sector agrícola en todo el país (como salario mínimo, un máximo de ocho horas de jornada laboral, vacaciones pagas, prohibición del trabajo infantil, condiciones laborales adecuadas, entre otras).

En el gobierno nacional aparecieron divisiones. Algunas áreas del gobierno nacional (particularmente el Ministerio de Economía), no querían entrar en conflicto con los empresarios del sector, ni con los gobernadores y legisladores de las provincias agrícolas. Según un funcionario de alto rango en el área de Relaciones Laborales del Ministerio de Trabajo del gobierno nacional y de la Comisión Nacional de Trabajo Agrícola, "Los empresarios del sector nos llamaban y nos trataban de delirantes. ${ }^{15} \mathrm{El}$ proyecto avanzó por la fortaleza de la alianza nacional, sostenida por miembros relevantes de la élite política-profe- 
sional, como el Ministro de Trabajo y áreas clave de la presidencia, además de los legisladores necesarios para debatirlo en el Congreso Nacional.

El aspecto más controvertido del nuevo proyecto de ley fue definir quién estaba a cargo del control del cumplimiento de los derechos laborales. ${ }^{6}$ Hasta entonces, el control estaba en manos del Registro Nacional de Trabajadores Rurales y Empleadores (RENATRE) y su operatoria subcontratada a una empresa privada. Durante la gestión de Gerónimo "Momo" Venegas al frente del sindicato rural (Unión Argentina de Trabajadores Rurales y Estibadores, UATRE) y del Renatre (2002-2011), la fiscalización fue tercerizada a una empresa vinculada al exgobernador de Buenos Aires y aliado de Venegas, Eduardo Duhalde (Premici 2015b; 2016). ${ }^{7}$ Un funcionario de alto rango del Ministerio Federal de Trabajo afirmó que, en esos momentos, "no notarías la diferencia entre el empresario y el líder sindical," y que además "se había dejado al lobo cuidando las gallinas." "Al RENATRE lo gobernaban empresarios y sindicatos, sin el gobierno nacional."

El resultado era el esperado teniendo en cuenta la coalición que, en su momento, había definido los detalles del control por parte del RENATRE: mucho empleo informal no era denunciado, particularmente en las grandes empresas o grandes campos. El estado nacional no participaba del control (lo hacía el sindicato y representantes de las empresas). Diputados opositores se encargaron de enfatizar que "el control es potestad de los Ministerios de Trabajo provinciales y no del Ministerio de Trabajo de la Nación, ya que las provincias nunca delegaron esa facultad" (DSCD: 327).

En el nuevo proyecto de ley, el gobierno nacional estaría a cargo de controlar el cumplimiento de las leyes federales. Para ello, se reemplazaba el RENATRE por el Registro Nacional de Trabajadores y Empleadores Agrarios (RENATEA).

Como era de esperar, algunos gobernadores y legisladores nacionales de provincias con grandes plantaciones resistieron enérgicamente al proyecto de ley. ${ }^{9}$ Según los diarios de sesiones, los diputados del Peronismo Federal (Aspiazu, Mouillerón, Rivara y Solá), opositores al Gobierno, y el senador del PJ Carlos Menem votaron en contra del proyecto. Los legisladores de la UCR votaron a favor del proyecto en general, pero votaron en contra de los artículos que establecía una nueva organización encargada del control, el RENATEA. En los fundamentos de la decisión del bloque legislativo de la UCR denunciaron la

\footnotetext{
Ver Diario de Sesiones de la Honorable Cámara de Diputados de la Nación, período 129, 13a reunión, 15 de diciembre de 2011.

Ver también Página 12 (2011). Entrevista con un funcionario de alto rango en el área de Planificación de la Política Laboral, Ministerio de Trabajo, Buenos Aires, 22 de noviembre de 2018; Entrevista con inspector federal del RENATEA, Resistencia, Chaco, 5 de abril de 2019; Entrevista con un funcionario de alto rango en el área de Relaciones Laborales, Ministerio de Trabajo y la Comisión Nacional de Trabajo Agrícola, Buenos Aires, 24 de julio de 2019 bre de 2018; 24 de julio de 2019; Entrevista con ex gobernador del Chaco, 5 de abril de 2019.
} 
premura del tratamiento y el revanchismo con el sindicato UATRE (Venegas fue crítico del gobierno de los Kirchner, aliado al peronismo opositor y a la oposición de centro derecha y participó activamente en movilizaciones rurales contra el gobierno en 2008) (DSCD: 318-319, 321-322, 327).

Como vemos, antes que partidarias, las divisiones estuvieron asociadas a las grandes coaliciones y alianzas redistributivas en Argentina. Los legisladores del Peronismo Federal y los gobernadores peronistas opositores al proyecto (como Puerta en Misiones y Urtubey en Salta), además de algunos legisladores de la UCR y sindicalistas de UATRE estuvieron más vinculados a los intereses de la coalición distributiva en la que participaron empresarios agrícolas que a los de los trabajadores rurales en este periodo. De allí que analizar las alianzas entre gobierno nacional, legisladores y gobernadores partir de divisiones partidarias esconde los clivajes y coaliciones distributivas clave del periodo.

A pesar de estas presiones de los gobernadores y legisladores opositores y sindicalistas de UATRE (que protestaron violentamente frente al Congreso), el proyecto se aprobó y sancionó en diciembre de 2011 (como ley 26,727; Régimen del Trabajo Agrario). Después de la sesión en el Congreso, el Ministro de Trabajo nacional, Carlos Tomada, declaró que "quienes más se opusieron al proyecto de ley fueron los que siempre tuvieron una actitud de desprecio y explotación de los trabajadores rurales (...) llegando a situaciones extremas de degradación y esclavitud (...). Este es el sector económico con la mayor proporción de mano de obra informal en el país." "La legislación anterior no hizo nada para revertir eso" (Página 12 2011b).

\section{Alianzas gobernantes subnacionales y enfrentamiento en el territorio}

Después de perder la batalla en la arena legislativa del nivel nacional, los gobernadores de las grandes provincias de plantaciones, controladas por coaliciones regresivas, asumieron la estrategia de resistir el control federal de esta legislación en sus territorios. "(La ley) salió por un tubo (i.e., muy rápido) en el Congreso, pero las provincias resistieron en sus territorios. (...) El enfrentamiento se dio en el territorio." Estos gobiernos provinciales "querían mantener el status quo," estaban "comprometidos a proteger el sector productivo" y "preocupados por el impacto en la producción." Argumentaban que "nadie va a querer invertir" y que "la gente (en la provincia) vive de esto." "Los empresarios del tabaco llamaban al ministro (de Trabajo, Carlos Tomada) y le preguntaban si (los funcionarios del gobierno) estaban locos."10

Los sectores productivos en que los actores clave están muy centralizados y coordinados, como el tabacalero, con las empresas nucleadas en la Cámara del

10 Entrevista con un funcionario de alto rango en el área de Relaciones Laborales, Ministerio Federal de Trabajo y la Comisión Nacional de Trabajo Agrícola, Buenos Aires, 24 de julio de 2019. 
Tabaco, ejercieron mucha presión sobre los gobiernos provinciales. "La Cámara del Tabaco de Salta era para mí el gobierno de Salta. No veía ninguna diferencia. Los ministros eran de la Cámara. Fueron totalmente refractarios a la ley. Lo mismo pasaba con los empresarios de la yerba, donde hay pocas empresas."11

La ley reconoció derechos laborales básicos a nivel nacional, pero dio poca capacidad de control al gobierno nacional en las provincias. La inspección y el control estuvieron dispersos, divididos entre provincias y gobierno nacional. La efectividad de estas funciones de control dependió de la colaboración o resistencia de los gobiernos provinciales.

\section{El caso de Corrientes: coalición regresiva provincial y alta desigualdad}

En el período de análisis, Corrientes estuvo gobernada por la UCR desde 1999 (dos interventores federales y cuatro gobernadores electos) en el marco de una alianza regresiva provincial. Esta alianza se evidencia en la composición del gabinete provincial.

El Ministerio de Producción ha sido asignado tradicionalmente a un empresario agrícola (generalmente de los sectores de arroz, tabaco o yerba mate). El ministro durante el periodo estudiado, el ingeniero Jorge Vara, representó al sector arrocero (fue presidente de la Cámara Nacional del Arroz) y fue seleccionado entre empresarios agrícolas y propuesto al gobernador. El director del banco provincial (Banco de Corrientes) generalmente representa al sector ganadero o grandes empresas agrícolas o de servicios (transporte). ${ }^{12}$

Las cámaras empresariales han estado históricamente presentes en el diseño de la política económica de la provincia. El Ministro de Producción tiene una junta asesora (Unidad Operativa de Producción, UOP) compuesta por delegados de las cámaras de negocios donde hay un representante de cada área productiva de los sectores agrícola y ganadero (El Litoral 2010). El ministro y la junta también asesoran al vicegobernador en políticas económicas para el sector. "Hay una articulación muy fuerte entre el gobierno y las élites agrícolas en la provincia." 13

Los sindicatos no han tenido participación en el gabinete en el periodo post-transición a la democracia, ni influencia sustancial en las políticas provinciales. Algunos sindicatos se aliaron con el PJ provincial y son parte de la oposición. Otros sindicatos, especialmente los del sector del transporte, se aliaron con el gobierno de Cambiemos (alianza entre UCR, PRO y otros partidos menores),

Íbid.

CV en línea de las Autoridades del Banco. Ver: https://www.bancodecorrientes.com.ar/sitio/seccion. php?id=27, accedida el 4 de abril de 2019. Entrevista con funcionario provincial en Corrientes, 16 de noviembre de 2018, 27 de marzo y 30 de marzo de 2019.

13 Entrevista con funcionario provincial en Corrientes, 16 de noviembre de 2018. 
pero nunca han tenido participación en el gabinete provincial ni una injerencia notoria en la orientación de las políticas púbicas provinciales.

Las élites económicas provinciales estuvieron muy coordinadas y han ejercido una gran influencia sobre el funcionamiento del estado provincial. En primer lugar, abordamos su influencia en la política subnacional (sin sus interacciones con el gobierno nacional), prestando atención a su rol en la regulación de los impuestos y el gasto social.

En relación a la política impositiva, el ministro y las Cámaras se reúnen anualmente para establecer la política fiscal para el sector agrícola y decidir si aumentan los impuestos al sector o no. Según la ley provincial 5,552, los ingresos tributarios totales recaudados del impuesto a la propiedad rural provincial se asignan a un fondo específico (el Fondo de Desarrollo Rural) que se reinvierte en el sector agrícola y ganadero; estos fondos, por ley, no pueden invertirse en otra área de gobierno.

En relación con el tipo de gasto, deberíamos esperar que esta alianza no priorice gasto social. Corrientes invirtió alrededor de 700 USD per cápita durante 1993-2013. Chaco invirtió 32 por ciento más (925 USD). Si nos concentramos durante el período clave en el que una alianza redistributiva progresiva controló el gabinete en Chaco (después de 2006), el gobierno de esta provincia invirtió un 49 por ciento más en gasto social que Corrientes (el promedio para Chaco fue de 1,484 USD y 995 USD para Corrientes).

Pero como argumentamos, la alianza entre élites económicas y políticas en el gobierno no solo ha influido en las políticas tributarias y en la estructura del gasto en las provincias. También, en segundo lugar, han resistido la efectiva implementación de las leyes laborales federales cuando estas se orientaron a mejorar las condiciones de los trabajadores rurales. Esta resistencia a las leyes nacionales en Corrientes no fue solamente consecuencia de una menor capacidad estatal (Amengual 2016) o de la falta de alineación política entre el oficialismo nacional (PJ) y un partido de oposición (UCR) (Niedzwiecki 2018) ni de la mayor conflictividad social en un caso respecto de otro (Calvo y Moscovich 2017; Fernández Milmanda y Garay 2019).

La provincia de Corrientes resistió los controles requeridos por el nuevo estatuto de los trabajadores rurales y colaboró muy poco con los inspectores nacionales. Los inspectores del RENATEA eran agentes públicos nacionales (federales) que tenían la potestad de inspeccionar el cumplimiento de los requisitos fijados en la norma que regulan la situación laboral de los trabajadores rurales. En caso de infracciones, labraban actas y multas. Pero necesitaban el apoyo material, logístico y hasta de seguridad de las provincias para realizar sus tareas. Y las provincias podían negar este apoyo. Uno de los inspectores federales que examinó las condiciones de trabajo en el sector agrícola y evaluó el cumplimiento de las leyes laborales federales en Chaco y Corrientes, sostuvo que, en Corrientes, "el 
poder político provincial no podía estar a favor de algo que iba en contra de sus intereses." 14

La provincia no colaboró con el control de la ley federal y el sector resistió todo lo que pudo en el territorio. Al entrar a controlar en algunos campos, los cuidadores "incendiaron camionetas, se dieron casos en los que hubo tiros (disparos de armas de fuego)."15 Según cuenta un inspector del RENATEA, era común ir al campo y que los "corran con machetes. Por eso a veces íbamos con gendarmería." Una vez, "los dueños (de un campo) se quisieron escapar con los trabajadores por otra salida (del campo). Los frenó gendarmería. Hicimos un acta y preguntamos cuantas horas trabajaban. Los peones le preguntaron al patrón: 'patrón ¿cuántas horas trabajo?'"16 Premici (2015) documentó algo similar en el sector yerbatero: "los empresarios tienen la costumbre de mover a los tareferos según sus necesidades o urgencias frente a una inminente inspección."

Un indicador simple pero revelador es la cantidad de sanciones que tiene una provincia por infracciones al régimen laboral de los trabajadores rurales. Esas sanciones son registradas por los inspectores nacionales en el Registro Público de Empleadores con Sanciones Laborales (REPSAL). Muchas sanciones en una provincia es un indicador de la situación precaria en la que viven sus trabajadores rurales, particularmente si es un distrito que colabora poco y resiste mucho a los inspectores nacionales (indicaría que, a pesar de la resistencia, hay muchas infracciones por la alta informalidad y explotación laboral). ${ }^{17}$

A pesar de la resistencia provincial a las inspecciones, Corrientes tuvo 1,399 sanciones debido al incumplimiento de las regulaciones laborales federales (datos recopilados del REPSAL durante octubre y noviembre de 2018; sitio web de REPSAL consultado el 27 de noviembre de 2018). Chaco tuvo 32 por ciento menos sanciones que Corrientes (945). Las provincias de población equivalente tienen valores cercanos a los del Chaco (Santiago del Estero tiene 913 y Misiones 746 sanciones). Realizamos una búsqueda similar en abril de 2019 y los resultados son bastante consistentes: Corrientes tuvo 1,392 sanciones y Chaco 938 (sitio web de REPSAL; consultado el 4 de abril de 2019).

A pesar de que la alianza redistributiva nacional intentó proteger y controlar el cumplimiento de los derechos laborales de las/os trabajadoras/es agrícolas (algo que seguramente redundaría en menos desigualdad debido a la alta correlación entre empleo informal, empleo agrícola y el coeficiente de Gini), la coalición regresiva provincial resistió a la política redistributiva nacional en Corrientes. La coalición provincial en Chaco, como veremos en la próxima sección, la apoyó. Corrientes era una de las provincias más desiguales al comienzo

14 Entrevista con inspector federal del RENATEA, Resistencia, Chaco, 5 de abril de 2019.

15 Entrevista con un funcionario de alto rango en el área de Relaciones Laborales, Ministerio Federal de Trabajo y la Comisión Nacional de Trabajo Agrícola, Buenos Aires, 24 de julio de 2019.

16 Entrevista con inspector federal del RENATEA, Resistencia, Chaco, 5 de abril de 2019.

17 Entrevista con un funcionario de alto rango en el área de Planificación de la Política Laboral, Ministerio de Trabajo, Buenos Aires, 22 de noviembre de 2018. 
de la serie de datos que tenemos; a pesar de la baja en la desigualdad en el período analizado, terminó entre las dos provincias más desiguales del país en el periodo analizado. ${ }^{18}$

\section{El caso del Chaco: coaliciones redistributivas (nacional y provincial) y baja en la desigualdad}

Desde la transición a la democracia, Chaco estuvo gobernada la mayor parte del tiempo por una alianza redistributiva progresiva. Sus gobernadores y miembros del gabinete después de la transición a la democracia (1983-2015) fueron, en su enorme mayoría, élites políticas, en lugar de élites económicas, aliadas con representantes de sindicatos y movimientos sociales, particularmente durante los mandatos de los gobernadores peronistas.

Aproximadamente el 75 por ciento de los miembros del gabinete ocuparon otros puestos anteriores en el poder ejecutivo provincial y otro 19 por ciento desempeñó funciones en el poder legislativo provincial (Castellani 2018: 7). El criterio principal para la selección de los miembros del gabinete ha sido tener una carrera política previa en el sector público. En promedio, los miembros del gabinete (ministros o secretarios) ocuparon alrededor de tres puestos en cargos públicos antes de acceder a los suyos, principalmente a nivel provincial, en posiciones administrativas o en cargos públicos. El promedio más alto fue durante el primero gobierno de Jorge Capitanich, con 7,8 puestos por persona en promedio antes de acceder al gabinete provincial.

Muy pocos miembros de la élite económica ocuparon posiciones en el gabinete provincial en Chaco. Aunque irrelevante en términos cuantitativos, el sector agrícola es el principal origen entre los funcionarios con un perfil completamente privado. De todos los cargos del gabinete, el que ha presentado la mayor relación con empresas o corporaciones es el Ministerio de Producción (antiguo Ministerio de Agricultura y Ganadería), especialmente durante las gobernaciones de la UCR y Acción Chaqueña, entre 1991 y 2003. Durante este periodo, el presidente de la Sociedad Rural del Chaco fue designado como ministro de Agricultura y Ganadería y empresarios ganaderos en el Ministerio de Producción (Castellani 2018: 14, 17, 24).

A diferencia de Corrientes, representantes de sindicatos, tanto de empleados públicos como del sector transporte y movimientos sociales, particularmente los representantes de trabajadoras/es informales, tuvieron puestos importan-

18 Si bien los datos disponibles de desigualdad subnacional nos permiten analizar solamente el periodo 20032011, en el mismo podemos observar la gran caída de la desigualdad en Chaco y la menos importante reducción en la de Corrientes. Datos agregados nacionales de desigualdad (no disponibles por provincia) indican un aumento de la desigualdad en los últimos años del gobierno de Cristina Fernández y durante el gobierno de Mauricio Macri. A pesar de este cambio en la tendencia, podemos sostener (debido a un fuerte componente inercial en la desigualdad) que difícilmente la diferencia de diez puntos de Gini entre las dos provincias haya cambiado sustantivamente. 
tes en el gobierno provincial cuando se dio un cambio en el signo partidario de las élites políticas gobernantes. Por ejemplo, Capitanich nombró en Desarrollo Social a la Secretaria General del gremio estatal más importante de la provincia, la Unión del Personal Civil de la Provincia, y a funcionarios gremiales en áreas clave del Ministerio de Educación (Castellani 2018: 11, 21) y en el de Transporte.

Estas élites políticas, aliadas con sindicatos y movimientos sociales, han implementado políticas redistributivas y han tenido más autonomía política en relación con las políticas que afectan al sector privado, como la regulación de los impuestos y las políticas sociales. Como se indicó en el análisis de Corrientes, Chaco invirtió un 49 por ciento más en gasto social que Corrientes durante el período clave en el que las élites políticas dominaron el gabinete en Chaco (después de 2006).

Pero, además, Chaco colaboró en el control de los derechos de los trabajadores agrícolas en la provincia. La delegación Chaco del RENATEA se abrió en abril de 2012. En la mayoría de las provincias se hizo en 2013. Según un inspector federal del RENATEA, "estaba la ley, pero no había presupuesto. Hubo sólo dos inspectores y una sola camioneta para las dos provincias (Chaco y Corrientes)." Pero en Chaco, "el gobierno provincial ayudó" implementando y cumpliendo con las leyes laborales federales. Franco Capitanich, primo del gobernador, estuvo en el área del gobierno provincial que tenía a cargo la coordinación con los inspectores federales. ${ }^{19}$

En Chaco, las leyes federales que regulan los derechos de los trabajadores rurales se cumplieron mucho más que en Corrientes. Como vimos, Chaco tuvo un 32 por ciento menos de sanciones laborales federales que esta última provincia.

El efecto neto de una alianza redistributiva nacional coordinada con una igual en la provincia es una menor desigualdad en ese territorio. De hecho, esperaríamos una reducción en la desigualdad mayor que la caída promedio nacional. Chaco tuvo valores relativamente altos de desigualdad en el primer año de la serie (0.52 en 2003). Desde 1989 y hasta el comienzo de los 2000, el país estuvo gobernado por una alianza pro-mercado y regresiva a nivel nacional, que aumentó estrepitosamente la desigualdad: el Gini de Argentina en el periodo paso de 0.45 en 1988 a 0.53 en 2003. Este fue el período en el que Chaco tuvo más élites económicas en el gabinete (1991-2003). No fue solo alineación política lo que produjo esta regresión redistributiva, sino también los intereses comunes de dos coaliciones regresivas similares en los dos niveles, gobernando al mismo tiempo. Sin embargo, esta tendencia se revirtió durante la década de 2000, cuando gobernaron coaliciones redistributivas tanto a nivel nacional como en la provincia. Como esperaríamos, Chaco bajó su índice de Gini en 16 puntos, llegando a 0.36 en 2011. Hoy, está dentro del grupo de las provincias menos desiguales de Argentina. 


\section{COMENTARIOS FINALES}

Una posible conclusión de este trabajo es que, en primer lugar, las políticas distributivas nacionales son afectadas sustancialmente en su implementación y efectos por las alianzas gobernantes en el nivel subnacional. Como muestra el caso de Corrientes, incluso una política nacional con nítidos rasgos redistributivos puede verse en buena medida neutralizada o fuertemente debilitada por una alianza regresiva subnacional.

En segundo lugar, la orientación regresiva o progresiva de estas alianzas tiene ciertamente un arraigo histórico-estructural que remite tanto a su estructura económica como a los rasgos que asume desde sus inicios el estado en términos de mayor o menor autonomía en un distrito subnacional.

La relevancia de las alianzas de gobierno provinciales sobre la incidencia de las políticas nacionales (en este caso progresivas) da sustento empírico, si bien inicial y provisorio, pero sobre todo razonabilidad teórica, a la hipótesis que la diferencia en la desigualdad entre Chaco y Corrientes no fue solamente consecuencia de la colaboración en política social entre aliados o de conflictos por tensiones partidarias entre oficialismo y oposición en la implementación de la política social (Niedzwiecki 2018), o de la mayor conflictividad social en un caso en relación al otro (Calvo y Moscovich 2017; Fernández Milmanda y Garay 2019) sino que también fue el resultado de la interacción (conflictiva o de cooperación) en cuanto a las políticas nacionales de las alianzas que gobernaron el país y estas provincias durante el período estudiado. Creemos que esta hipótesis y la evidencia empírica en los casos sobre las interacciones entre alianzas redistributivas puede abrir una agenda de futuras indagaciones (tanto cualitativas como cuantitativas) orientadas a verificar y especificar los detalles de la incidencia de estas alianzas de gobierno provinciales sobre las desigualdades, no sólo de ingresos sino también de otro tipo.

Finalmente, la existencia e influencia de alianzas gobernantes relativamente exitosas no son contradictorias con la vigencia de más o menos amplios grados de autonomía estatal arraigada no sólo en una estructura burocrática, sino también en élites políticas con intereses político-electorales bien definidos. Esta "doble cara" de las alianzas gobernantes (una social-corporativa, asociada a los intereses vigentes en la imagen de la producción, y otra política, vinculada al juego político electoral) permite una nueva mirada respecto del vínculo, presente en buena parte de la literatura, entre los signos político-ideológicos de los gobiernos y la desigualdad: estos signos no son irrelevantes, pero interpretarlos por fuera del contexto social, productivo y político subnacional en el que operan puede llevar a simplificaciones engañosas. 


\section{REFERENCIAS}

Acemoglu, Daron y James A. Robinson. 2006. Economic Origins of Dictatorship and Democracy. New York: Cambridge University Press.

Alcañiz, Isabela y Ricardo A. Gutierrez. 2020. “Between the Global Commodity Boom and Subnational State Capacities: Payment for Environmental Services to Fight Deforestation in Argentina." Global Environmental Politics 20(1): 38-59.

Amengual, Matthew. 2016. Politicized Enforcement in Argentina: Labor and Environmental Regulation. New York: Cambridge University Press.

Ansell, Ben W. y David J. Samuels. 2014. Inequality and Democratization. New York: Cambridge University Press.

Balán, Jorge. 1978. “Una Cuestión Regional en la Argentina: Burguesías Provinciales Y El Mercado Nacional en El Desarrollo Agroexportador." Desarrollo Económico 18(69): 4987.

Behrend, Jaqueline. 2011. "The Unevenness of Democracy at the Subnational Level: Provincial Closed Games in Argentina." Latin American Research Review 46(1): 150-176.

Benton, Allyson L. 2003. "Presidentes Fuertes, Provincias Poderosas: La Economía Política de la Construcción de Partidos en El Sistema Federal Argentino." Política y Gobierno 10: $103-137$

Beramendi, Pablo, Mark Dincecco y Melissa Rogers. 2016. "Intra-Elite Competition and Long-Run Fiscal Development." Working Paper. Recuperado el 16 de febrero de 2020 de https://ssrn.com/abstract=2837072

Beramendi, Pablo, Melissa Rogers y Alberto Díaz-Cayeros. 2017. Barriers to Egalitarianism. Latin American Research Review 52(4): 529-551.

Blofield, Merike. 2011. The Great Gap: Inequality and the Politics of Redistribution in Latin America. University Park: Penn State Press.

Bucciarelli, Mario y Orietta Favaro. 2008. "Neuquén (Argentina) ¿Economía de Enclave Y Estado de Bienestar?" Realidad Económica 238: 95-119.

Calvo, Ernesto y Lorena Moscovich. 2017. "Inequality, Protests, and the Progressive Allocation of Cash Transfers in the Argentine Provinces." Latin American Politics and Society 59(2): 3-26.

Castellani, Ana. 2018. "Estudio Socio-Histórico de Los Gabinetes Provinciales." Artículo de Investigación, Resistencia: Escuela de Gobierno de Chaco.

Cao, Horacio y Josefina Vaca. 2006. “Desarrollo Regional en la Argentina: La Centenaria Vigencia de Un Patrón de Asimetría Territorial." Revista Eure 32(95): 95-111.

Chazarreta, Adriana S. 2012. "El Abordaje de Las Desigualdades en Un Contexto de Reconversión Socio-Productiva. El Caso de la Inserción Internacional de la Vitivinicultura de la Provincia de Mendoza, Argentina." Research Network on Interdependent Inequalities in Latin America: Working Paper N. 19.

Collado, Patricia A. 2006. “Desarrollo Vitivinícola en Mendoza-Argentina. Apuntes Sobre Su Origen." Trabajo y Sociedad 8(7): 1-28.

Dahl, Robert A. 1961. Who Governs? Democracy and Power in an American City. New Haven: Yale University Press.

Diario de Sesiones de la Honorable Cámara de Diputados de la Nación (DSCD), Período 129, 13a Reunión, 15 de diciembre de 2011. Recuperado el 4 de abril de 2019 de https:/ / www.hcdn.gob.ar/secparl/dtaqui/diario_sesiones/acordeon.html

Dirección de Desarrollo Agropecuario (DDA). 2007. “Proyecto de Desarrollo de Pequeños Productores Agropecuarios (Proinder), Los Pequeños Productores en la República Argentina." Recuperado el 4 de abril de 2019 de http:/ / repiica.iica.int/docs/B0676e/ B0676e.PDF

El Litoral. 2010, 10 de abril. "Inició su labor la Unidad Operativa de Producción." Recuperado el 4 de abril de 2019 de https:/ /www.ellitoral.com.ar/corrientes/2010-4-10-21-0-0inicio-su-labor-la-unidad-operativa-de-produccion.

Fairfield, Tasha. 2015. Private Wealth and Public Revenue. New York: Cambridge University Press. 
Fernández Milmanda, Belén y Candelaria Garay. 2019. "Subnational Variation in Forest Protection in the Argentine Chaco." World Development 118: 79-90.

Galor, Oded, Omer Moav y Dietrich Vollrath. 2009. "Inequality in Land Ownership, the Emergence of Human Capital Promoting Institutions, and the Great Divergence." Review of Economic Studies 76(143): 165-71.

Giraudy, Agustina, Eduardo Moncada y Richard O. Snyder. 2019. Inside Countries: Subnational Research in Comparative Politics. New York: Cambridge University Press.

González, Lucas y Marcelo Nazareno. 2018. “La Desigual Distribución de la Desigualdad. Política Subnacional Y Distribución Del Ingreso en Las Provincias Argentinas, 20032011." Revista de la SAAP 13(1): 43-76.

González, Lucas y Marcelo Nazareno. 2021. "Resisting Equality: Subnational State Capture and the Unequal Distribution of Inequality". Comparative Politics (en prensa).

Gourevitch, Peter. 1993. Políticas Estratégicas en Tiempos Difíciles. Respuestas Comparativas a Las Crisis Económicas Internacionales. México: Fondo de Cultura Económica.

Hacker, Jacob S. y Paul Pierson. 2010. Winner-Take-All Politics: How Washington Made the Rich Richer--and Turned Its Back on the Middle Class. New York: Simon and Schuster.

Holland, Alisha C. 2016. "Forbearance." The American Political Science Review 110(2): 232-246.

Huber, Evelyne y John D. Stephens. 2012. Democracy and the Left: Social Policy and Inequality in Latin America. Chicago: University of Chicago Press.

Iversen, Torben y David Soskice. 2006. "Electoral Institutions and the Politics of Coalitions: Why Some Democracies Redistribute More Than Others." American Political Science Review 100(2): 165-181.

Kelly, Nathan J. y Christopher Witko. 2012. "Federalism and American Inequality." The Journal of Politics 74(2): 414-426.

Lupu, Nohan y Jonas Pontusson. 2011. "The Structure of Inequality and the Politics of Redistribution." American Political Science Review 105(2): 316-336.

Mann, Michael. 2004. "La Crisis Del Estado-Nación en América Latina." Desarrollo Económico 44(174), 179-198.

MECON (Ministerio de Economía y Finanzas Públicas), Dirección Nacional de Asuntos Provinciales. 2018. Corrientes. Informe Sintético de Caracterización Socio-Productiva. Recuperado el 4 de abril de 2019 de http:/ / www2.mecon.gov.ar/hacienda/dinrep/ Informes/archivos/corrientes.pdf

MECON, Dirección Nacional de Asuntos Provinciales. 2018b. Chaco. Informe Sintético de Caracterización Socio-Productiva. Recuperado el 4 de abril de 2019 de http:/ / www2. mecon.gov.ar/hacienda/dinrep/Informes/archivos/chaco.pdf

Moore, Barrington. 1966. Social Origins of Dictatorship and Democracy: Lord and Peasant in the Making of the Modern World. Boston: Beacon Press.

Niedzwiecki, Sara. 2018. Uneven Social Policies: The Politics of Subnational Variation in Latin America. New York: Cambridge University Press.

OCDE. 2019. Income Inequality (indicator). doi: 10.1787/459aa7f1-en. Recuperado el 24 de Septiembre de 2019 de https:/ / data.oecd.org/inequality/income-inequality.htm

O’Donnell, Guillermo. 1997. “Estado y Alianzas en la Argentina, 1956-1976." en Contrapuntos. Ensayos Escogidos Sobre Autoritarismo Y Democratización. Buenos Aires: Paidós

Page, Benjamin I., Larry M. Bartels y Jason Seawright. 2013. “Democracy and the Policy Preferences of Wealthy Americans." Perspectives on Politics 11(1): 51-73.

Página 12. 2011, 22 de diciembre. "Con todos los derechos de los otros trabajadores." Recuperado el 16 de febrero de 2020 de https://www.pagina12.com.ar/diario/elpais/1-183939-2011-12-22.html

Página 12. 2011b, 22 de diciembre. "Satisfacción de Tomada." Recuperado el 16 de febrero de 2020 de https://www.pagina12.com.ar/diario/elpais/subnotas/183939-57099-2011-12-22.html

Pardelli, Giuliana. 2018. "Agrarian Elites, Economic Diversification and Local Fiscal Capacity." Paper Draft, Politics Department, Princeton University. 
Pierson, Paul. 1995. "Fragmented Welfare States: Federal Institutions and Development of Social Policy." Governance 8(4): 449-478.

Premici, Sebastián. 2015, 2 de mayo. “Viaje a la profundidad de la selva misionera," Página 12. Recuperado el 16 de febrero de 2020 de https://www.pagina12.com.ar/diario/ economia/2-271784-2015-05-02.html

Premici, Sebastián. 2015b, 2 de mayo. El mapa de la explotación laboral, Página 12. Recuperado el 16 de febrero de 2020 de https://www.pagina12.com.ar/diario/economia/ subnotas/271784-72562-2015-05-02.html

Premici, Sebastián. 2016. De Patrones y Peones. Buenos Aires: Acercándonos Ediciones.

Santos, Boaventura de Sousa. 2010. La Refundación Del Estado en América Latina. Perspectivas Desde Una Epistemología Del Sur. Lima: Instituto Internacional de Derecho

Sátyro, Natalia. 2013. "Política Estadual E Desigualdade: Por Que Alguns Estados Redistribuem Mais Do Que Outros?" Dados 56(3): 497-530.

Skocpol, Theda. 1989. “El Estado Regresa al Primer Plano: Estrategias de Análisis en la Investigación Actual." Zona Abierta 50: 71-121

Smulovitz, Catalina. 2015. "Legal Inequality and Federalism: Domestic Violence Laws in the Argentine Provinces." Latin American Politics and Society 57(3): 1-26.

Snyder, Richard O. 2001. "Scaling Down: The Subnational Comparative Method." Studies in Comparative International Development 36 (January): 93-110.

Socio-Economic Database for Latin America and the Caribbean (SEDLAC) (2018). Recuperado el 24 de Septiembre de 2019 de https:/ /www.cedlas.econo.unlp.edu.ar/wp/en/ estadisticas/sedlac/estadisticas/

Subsecretaría de Planificación Económica (SSPE). 2016. Informes Productivos Provinciales. Corrientes. Buenos Aires: Ministerio de Economía.

Tsebelis, George. 1991. Nested Games. Rational Choice in Comparative Politics. Berkeley: University of California Press.

UNU-WIDER, World Income Inequality Database (WIID4) (2018) Recuperadoel 24 deSeptiembre de 2019 de https:/ / www.wider.unu.edu/project/wiid-\%E2\%80\%93-world-income-inequality-database

Weitz-Shapiro, Rebecca. 2012. "What Wins Votes: Why Some Politicians Opt Out of Clientelism." American Journal of Political Science 56(3): 568-583.

Winters, Jeffrey A. 2011. Oligarchy. New York: Cambridge University Press, 2011.

Recibido: 4 de agosto de 2020

Aceptado: 3 de marzo de 2021

Lucas González. Doctor (Ph.D.) en Ciencia Política de la University of Notre Dame. Magíster en Ciencia Política de la University of Notre Dame. Magíster en Estudios Latinoamericanos de la Universidad de Oxford. Magíster en Políticas Públicas de Georgetown-UNSAM. Investigador adjunto del Consejo Nacional de Investigaciones Científicas y Técnicas (CONICET). Profesor adjunto en la Universidad Nacional de San Martín. Investigador principal en la Universidad Católica Argentina. Profesor e investigador visitante en Brown University, Australian National University, University of KwaZulu-Natal, Universidad de Salamanca y la Fundação Getulio Vargas. Correo electrónico: lgonzalez@unsam.edu.ar; lucas_gonzalez@uca.edu.ar

Marcelo Nazareno. Licenciado en Historia por la Unversidad Nacional de Córdoba (UNC), Magíster en Administración Pública por la UNC y Doctor en Ciencias Sociales por Flacso-Argentina. Profesor Titular de Teoría Política en la UNC y Profesor e Investigador en la Universidad Católica de Córdoba (UCC)-Unidad Asociada al CONICET. Director del Doctorado en Política y Gobierno de la UCC. Investigador Responsable del PICT 2019-00443 “Estado, Alianzas y Redistribución. Un estudio subnacional comparado de Argentina y Brasil, 2000-2020", acreditado y financiado por la Agencia Nacional de Promoción Científica, Fondo para la Investigación Científica y Tecnológica. Correo electrónico: nazareno@ucc.edu.ar 
